\title{
Evidence of earthquake-induced liquefaction obtained from GeoEye-1 images
}

\author{
M. PENDER*, L. WOTHERSPOON*, M. CUBRINOVSKI†, E. BOWMAN† and R. ORENSE*
}

\begin{abstract}
A most significant effect of the $M_{w} 7 \cdot 1$ Darfield earthquake of 4 September 2010 was widespread liquefaction and lateral spreading in the eastern parts of the city of Christchurch and the surrounding region. Large volumes of ejecta were deposited on the ground surface. A few hours after the earthquake, a GeoEye-1 image of part of the area affected by the earthquake was captured and subsequently appeared on Google Earth. Saturday 4 September was a clear day in Canterbury, so this image provided good evidence of liquefaction in the form of piles of ejected sand on the ground surface in Christchurch and the surrounding region. This letter illustrates the effectiveness of public domain GeoEye-1 images at indicating places where liquefaction has occurred. Not surprisingly, the colour contrast between the material ejected and the surface onto which the material was deposited was an important factor in identification. In addition, although a considerable volume of water was observed to have been ejected during the liquefaction, in some places, the images gave the impression that the extent of the liquefaction was much greater than was found to be the case during subsequent on-ground reconnaissance. These observations were confirmed following the $M_{\mathrm{w}} 6 \cdot 2$ Christchurch earthquake (an aftershock of the Darfield event) on 22 February 2011.
\end{abstract}

KEYWORDS: earthquakes; liquefaction; sands; silts

ICE Publishing: all rights reserved

\section{INTRODUCTION}

The $M_{\mathrm{w}} 7 \cdot 1$ Darfield earthquake occurred in Canterbury, New Zealand, at $0435 \mathrm{~h}$ on Saturday 4 September 2010 (local time and date). A most significant effect of the earthquake was widespread liquefaction and lateral spreading in the eastern parts of the city of Christchurch and the surrounding towns. Large volumes of ejecta, which consisted of silty sand $\left(D_{10}\right.$ between about 0.02 and $0.08 \mathrm{~mm}$ and $D_{60}$ between about 0.08 and $0.12 \mathrm{~mm}$ ), were deposited on the ground surface (Allen et al., 2010). On the day of the earthquake and in the following days and weeks, the authors visited Porritt Park in the Wainoni area of Christchurch several times and observed the extent of the ejected material there.

Figure 1 shows part of the GeoEye-1 (GeoEye-1 Inc., 2011) image covering Porritt Park (location about $43^{\circ} 30^{\prime} 57^{\prime \prime} \mathrm{S}$ and $172^{\circ} 41^{\prime} 08^{\prime \prime} \mathrm{E}$ ) (the image is dated 3 September because GMT rather than the local time and date in Christchurch is used by Google (Google Earth, 2010).) In addition, one of the authors viewed the area during a helicopter flyover on the afternoon of 10 September; Fig. 2 shows an image of Porritt Park obtained during that flyover. Comparison of Figs 1 and 2 indicates that both images show similar locations and extent of the piles of ejecta. Looking at other parts of eastern Christchurch in the GeoEye-1 image, it was apparent that there was also liquefaction and lateral spreading at Avon Park (location about $43^{\circ} 31^{\prime} 06 \cdot 74^{\prime \prime} \mathrm{S}$ and $172^{\circ} 40^{\prime} 45^{\prime \prime} \mathrm{E}$ )

Manuscript received 25 October 2011; first decision 15 December 2011; accepted 22 May 2012

Published online at www.geotechniqueletters.com on 20 June 2012.

${ }^{*}$ Department of Civil and Environmental Engineering, University of Auckland, Auckland, New Zealand

$\dagger$ Department of Civil and Resource Engineering, University of Canterbury, Christchurch, New Zealand and Sullivan Park (location about $43^{\circ} 30^{\prime} 57 \cdot 5^{\prime \prime} \mathrm{S}$ and $172^{\circ} 40^{\prime} 10^{\prime \prime} \mathrm{E}$ ) (images of these two parks are not included in this letter). On-ground inspection of Sullivan Park by two of the authors on 13 and 28 September and Avon Park on 28 September verified that there was indeed sand ejected from lateral spreading fissures at these two sites.

The work of Bray \& Frost (2010: chapter 3) illustrates how a comparison of before and after satellite images clearly indicates the damage caused by the tsunami that followed the Maule earthquake in Chile in February 2010. This letter provides a further example of the potential usefulness of satellite images in geotechnical practice. Simple visual observation of the images is considered herein; that is not to say that further information could not be gleaned from the images by employing image analysis techniques.

\section{GEOEYE IMAGES}

The main reason the GeoEye-1 images are effective at indicating liquefaction is that the light colour of the ejected sand contrasts very well with the underlying green turf at Porritt, Avon and Sullivan Parks. However, areas where the surface onto which the sand was ejected does not have a good colour contrast do not give such a clear indication of liquefaction in the GeoEye-1 image. Bexley is a recent subdivision near the mouth of the Avon River (location about $43^{\circ} 30^{\prime} 49^{\prime \prime} \mathrm{S}$ and $172^{\circ} 43^{\prime} 16^{\prime \prime} \mathrm{E}$ ), which has been developed in stages since the early 1990s. All of the Bexley area was affected by liquefaction, but especially the area towards the south of the subdivision (location about $43^{\circ} 31^{\prime} 06^{\prime \prime} \mathrm{S}$ and $\left.172^{\circ} 43^{\prime} 17^{\prime \prime} \mathrm{E}\right)$. Here, large volumes of sand were ejected, much of it onto paved surfaces (Fig. 3(b)). With knowledge that there was ejected sand in these areas, one could look carefully at the GeoEye-1 image and note that the roadside kerbing and channelling, so clearly visible 


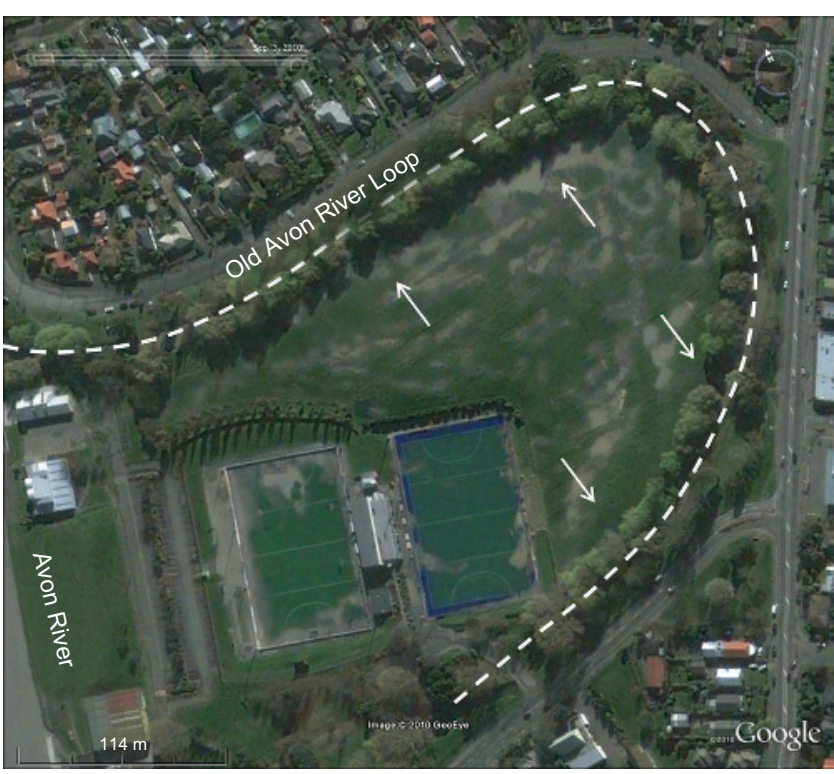

Fig. 1. Image of Porritt Park, Christchurch, extracted from the GeoEye-1 image taken a few hours after the Darfield earthquake with directions of lateral spreading shown (representative coordinates $43^{\circ} 30^{\prime} 57^{\prime \prime} \mathrm{S}$ and $172^{\circ} 41^{\prime} 08^{\prime \prime} \mathrm{E}$ )

in some of the earlier public domain GeoEye-1 images (e.g. that of 23 October 2009 shown in Fig. 3(a)), was no longer apparent in Fig. 3(b) in the same streets of the subdivision as in Fig. 3(a).

The polar orbit of the satellite (altitude about $680 \mathrm{~km}$ ) that acquires the GeoEye-1 images is such that the satellite passes over a particular part of the earth's surface at about $1030 \mathrm{~h}$ local time each pass. The best resolution of the images is stated to be $0.42 \mathrm{~m}$, available at approximately 8 day intervals, although lesser resolution can be obtained as frequently as every 2 days (the resolution depends on how close to vertically beneath the satellite the place being imaged is positioned) (GeoEye Inc., 2011). The images placed on Google Earth (Google Earth, 2010) of the region affected by the earthquake were processed to give the highest resolution. Current practice in New Zealand lays concrete street-side kerbing and channelling with typical widths of about $0.4-0.5 \mathrm{~m}$. This dimension, in relation to the earlier comment about the image for 23 October 2009, suggests that, at least for elongated objects, the resolution

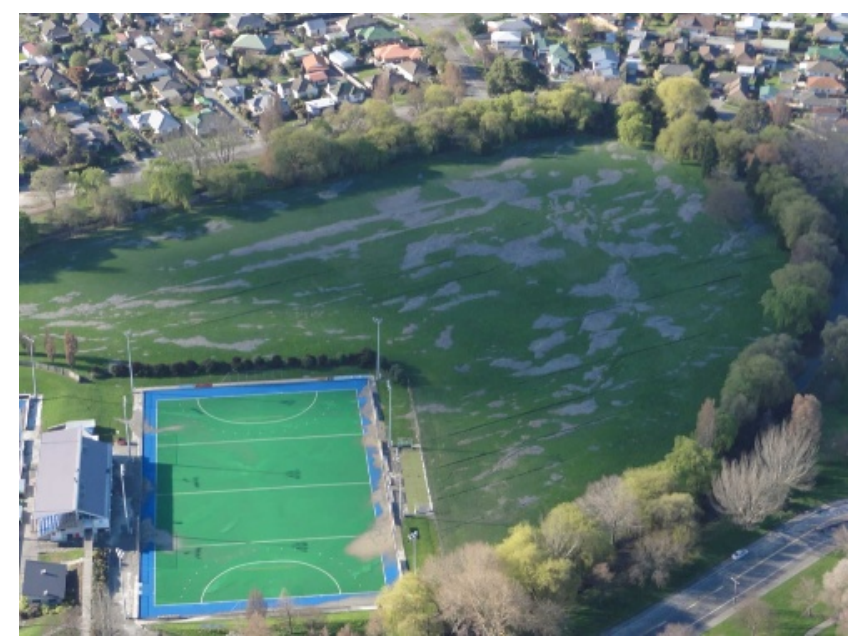

Fig. 2. Image of Porritt Park captured from a helicopter flyover on the afternoon of 10 September 2010 is indeed about $0.4 \mathrm{~m}$ as the kerbing and channelling is visible for many streets in Fig. 3(a). An indication that, with the right conditions, the resolution of the GeoEye-1 image may be rather better than $0.4 \mathrm{~m}$ is the clarity with which the hockey ground markings (width about $0.1 \mathrm{~m}$ ) can be seen in Fig. 1.

The resolution may also be related to the intensity of illumination from sunlight. For example, the image of the same area as shown in Fig. 1, dated 23 October 2009 but not included in this letter, shows the hockey ground markings even more crisply, but in that case the lighting over the whole image appears more intense than in Fig. 1. Given that the satellite passes over a particular place at about the same time of day, this difference in illumination may be because by 23 October the sun is higher in the sky than on 3 September - a consequence of the approaching southern hemisphere summer. Even so, the intensity of solar illumination in the image dated 3 September 2010 is sufficiently strong to cast shadows although, consistent with the previous sentence, these are longer than those for the 23 October 2009 image. Nevertheless, these observations confirm that, with the right ground lighting conditions, the GeoEye- 1 image has a resolution readily capable of resolving details of ground surface ejecta deposits - that is, what is seen in the images is a good representation of what is actually on the ground.

When looking at ejected material, it was noted that, typically, there is a layer of fine material on top that is lighter in colour than the underlying material. This lighter colour enhances the contrast with the surrounding turf, so making the liquefaction ejecta easier to recognise.

\section{EJECTED SAND AND EJECTED WATER}

Local residents commented that on the morning after the earthquake the Avon and Heathcote Rivers had taken on a milky appearance. One of the authors, living in Dallington an area of Christchurch with severe liquefaction - commented on the large amount of surface water that accompanied the ejected sand surrounding the houses. It was noted that when some of the ejected material was shaken with water in a measuring cylinder and left to settle, several hours passed before the water became clear. There was thus enough fine material in the ejected sand to explain the milky appearance of the local rivers and streams after the earthquake.

Part of the public domain GeoEye-1 image for 3 September covering the Halswell area, south-west of Christchurch, is shown in Fig. 4. This indicates many areas with the same light colouring as in Fig. 1, suggesting that there were many areas of Halswell that had extensive deposits of ejected sand. One of the authors visited Halswell on 29 September with printouts of the GeoEye-1 image of those parts of the area with the most extensive showing of light-coloured areas in the images. Large numbers of sandboils were visible in many of the fields surrounding Halswell as well as instances of modest lateral spreading along road and stream verges. Figure 5 shows images of two of the areas from Fig. 4 at a similar scale to Fig. 1. None of the marked areas in the two parts of Fig. 5 had areas of ejected sand of the extent of the light-coloured areas in the GeoEye-1 images. On 29 September 2010, the area marked A in Fig. 5(a) was examined carefully, by walking up the adjacent driveway, and only a small trace of surface water was observed in about the middle of the marked area. Examination of the area marked B showed no sign of ejected sand or water. However, discussion with the land-holder of the area marked $\mathrm{C}$ in Fig. 5(b) confirmed that what is seen on the GeoEye-1 image was water that, by 29 September had drained away. There was a small amount 


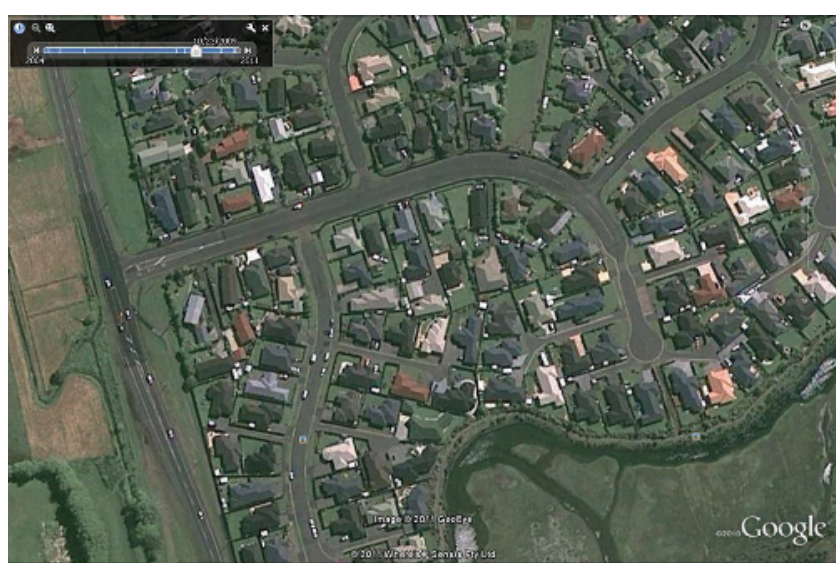

(a)

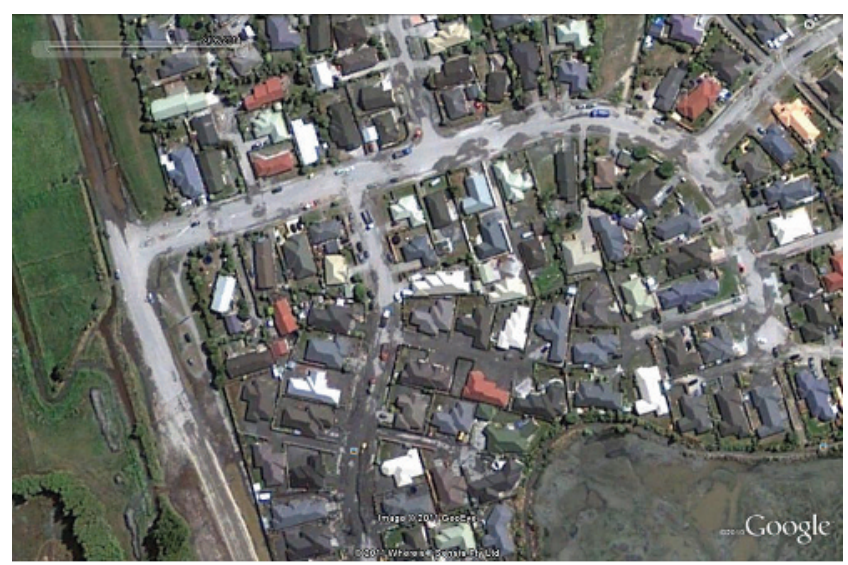

(b)

Fig. 3. (a) GeoEye-1 image of streets in the Bexley area (representative coordinates $43^{\circ} 31^{\prime} 04^{\prime \prime} \mathrm{S}$ and $172^{\circ} 43^{\prime} 17^{\prime \prime} \mathrm{E}$ ) taken on 23 October 2009 showing, in some places, the roadside kerbing and channelling. (b) GeoEye-1 image of the same streets as in Fig. 3(a) on 26 February 2011 showing how the ejected sand has obscured the kerbing and channelling

of surface water remaining in the area marked D. The landowner explained that this part of his property was prone to flooding whenever there was rain. Before the earthquake, the area was dry but the winter months had experienced more than the usual amount of rain so the water table would have been close to the ground surface. This water subsided within a few days of the earthquake and no sandboils were observed in the area marked C. However, there were many discrete sandboils in the areas marked $\mathrm{E}$ and $\mathrm{F}$, rather than elongated traces indicating lateral spreading. The ejection of large quantities of water along with sand has also been observed in other earthquakes where liquefaction was significant (Ishihara et al., 1993; JGS, 2004).

Returning to the comment above about how clearly the hockey field markings stand out in the images shown in Fig. 1, as these lines are so much narrower than the stated resolution of the GeoEye-1 image, the linear persistence must contribute to enhancing what can be seen. This effect will also carry over to material ejected during lateral spreading, which, as seen in Fig. 1, gives an elongated deposit. Looking at the racetrack (area E in Fig. 5(b)), sandboils were observed during visits, one on 11 September and another on 26 September. However, as these were discrete rather than elongated traces, with many boil 'diameters' less than $1 \mathrm{~m}$ and some even less than $0.5 \mathrm{~m}$, they are not clear on the GeoEye-1 image.

\section{FURTHER LIQUEFACTION ON FEBRUARY 22}

The 22 February aftershock to the Darfield earthquake was of lesser magnitude but the epicentre was much closer to Christchurch, so the ground motions were more intense and those areas that had liquefied on 4 September liquefied again. In addition, many areas with no liquefaction after 4 September now had extensive thick deposits of ejecta (Cubrinovski et al., 2011). One of the authors was in the Christchurch Central Business District when this event occurred. Walking out from the city afterwards, the milky colour of the Avon River was noted, confirming observations made by others after 4 September 2010.

Figure 6 shows two views of the Cashmere High School grounds (location about $43^{\circ} 34^{\prime} 00^{\prime \prime} \mathrm{S}$ and $172^{\circ} 37^{\prime} 22^{\prime \prime} \mathrm{E}$ ). Figure 6(a), dated 3 September 2010 (local date 4 September) shows that these grounds had not been affected by liquefaction after the Darfield earthquake. Figure 6(b) shows part of the GeoEye-1 image dated 26 February 2011, which shows extensive ejecta deposits, marked A and B, generated by new liquefaction after the Christchurch earthquake.

The GeoEye-1 images of ejecta in Bexley after 22 February were clearer than those taken after 4 September. Figure 3(a) gives a street view showing clearly the kerbing and channelling in October 2009 (location about $43^{\circ} 31^{\prime} 04^{\prime \prime} \mathrm{S}$ and $\left.172^{\circ} 43^{\prime} 17^{\prime \prime} \mathrm{E}\right)$. Figure $3(\mathrm{~b})$, of the same area, shows how the kerbing and channelling is obscured by ejected sand after 22 February but, under these lighting conditions, having a good contrast with the pavement beneath.

\section{IDENTIFICATION OF LIQUEFACTION IN REMOTE AREAS}

In a well-populated area such as Christchurch, GeoEye-1 images are not needed to provide evidence of liquefaction. What the images of Christchurch confirm though, is, that

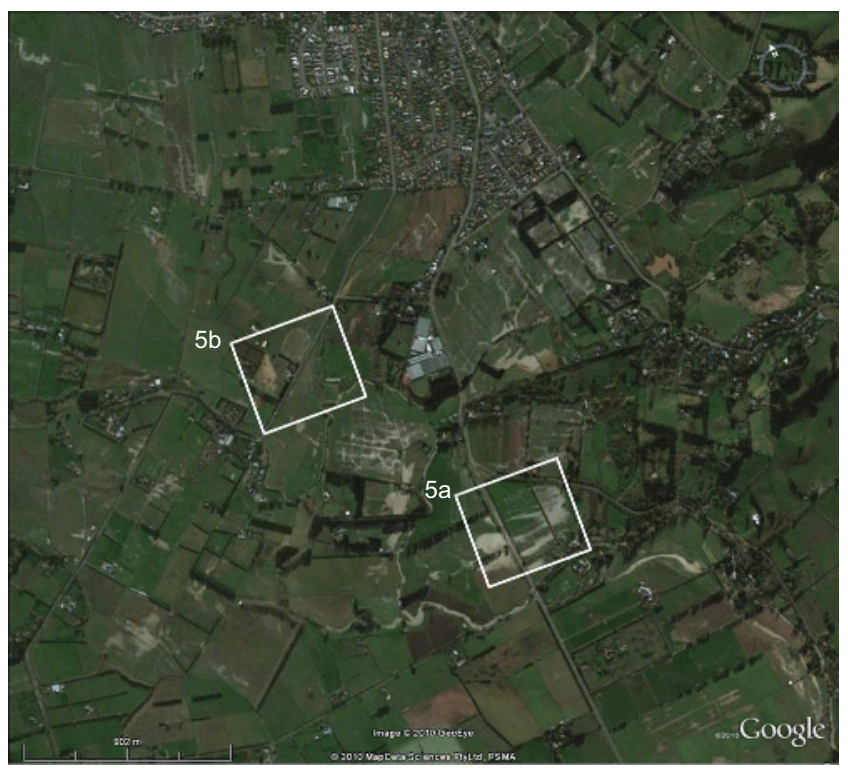

Fig. 4. Part of Halswell as imaged by GeoEye- 1 after the Darfield earthquake. The ejected sand is accompanied by considerable volumes of water forming mini-lakes having a similar colour to the ejected sand (representative coordinates $43^{\circ} 36^{\prime} \mathrm{S}$ and $\left.172^{\circ} 34^{\prime} \mathrm{E}\right)$ 


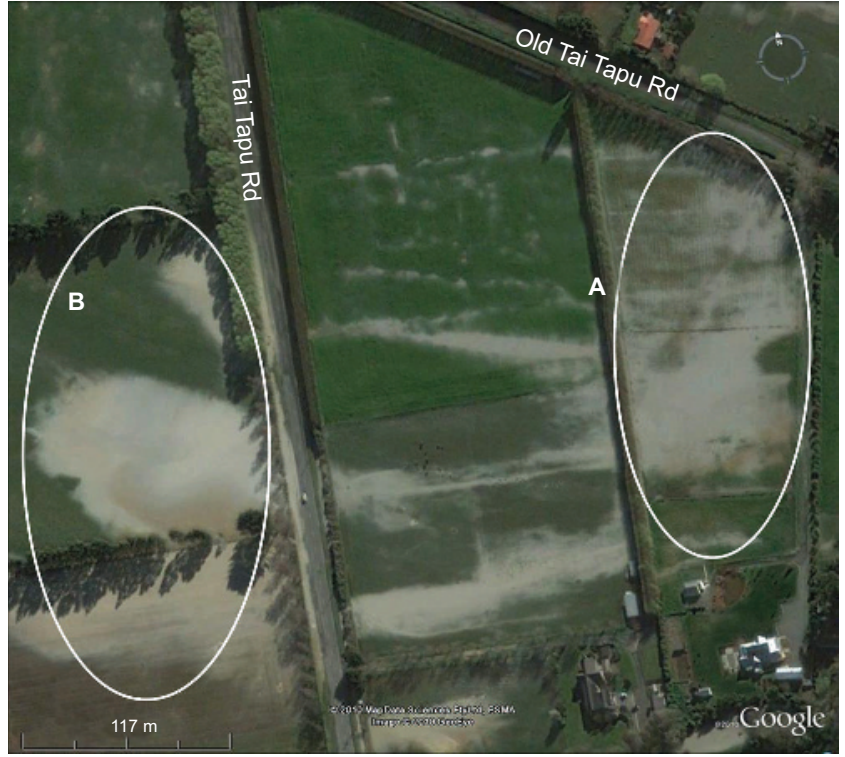

(a)

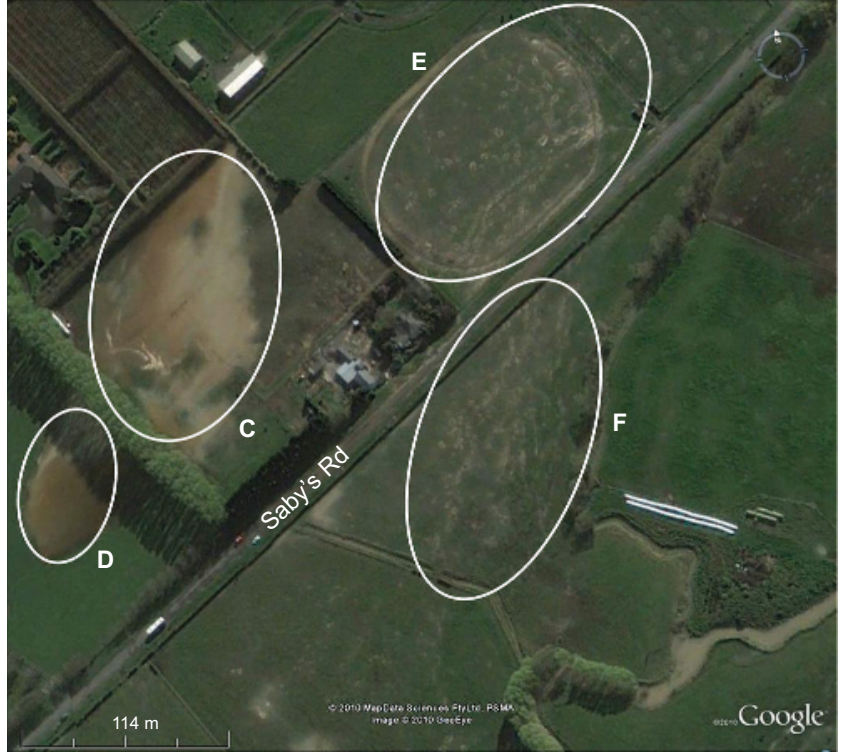

(b)

Fig. 5. Enlargements of portions of Fig. 4: (a) representative coordinates $43^{\circ} 36^{\prime} 16^{\prime \prime} \mathrm{S}$ and $172^{\circ} 33^{\prime} 37^{\prime \prime} \mathrm{E}$; (b) representative coordinates $43^{\circ} 35^{\prime} 40^{\prime \prime} \mathrm{S}$ and $172^{\circ} 33^{\prime} 10^{\prime \prime} \mathrm{E}$ (note the milky colour of the stream in the bottom right of the view)

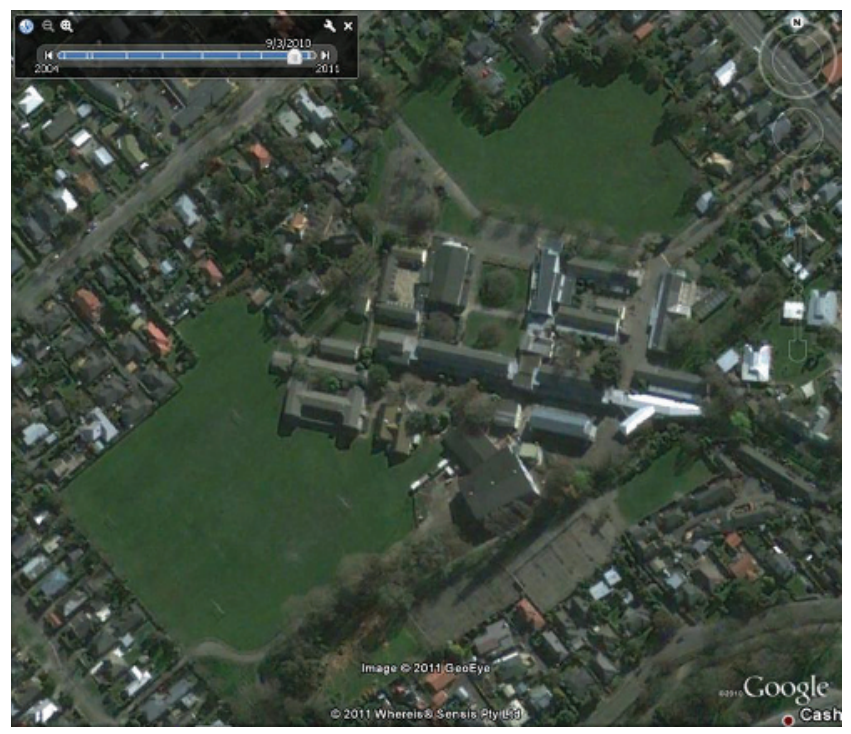

(a)

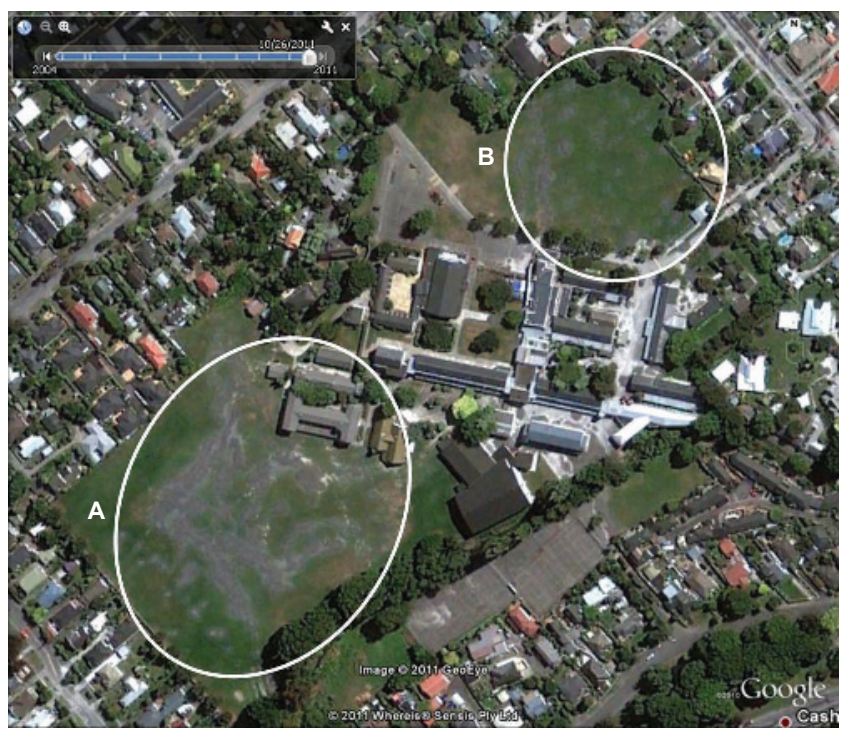

(b)

Fig. 6. (a) Cashmere High School grounds free of liquefaction deposits after the 4 September earthquake; representative coordinates $43^{\circ} 34^{\prime} 00^{\prime \prime} \mathrm{S}$ and $172^{\circ} 37^{\prime} 22^{\prime \prime} \mathrm{E}$. (b) Cashmere High School grounds with extensive deposits of ejected material (areas marked A and B) after the Christchurch earthquake; satellite image 26 February 2011, 5 days after the earthquake

with the right lighting conditions and satellite position, the imagery obtained is readily able to confirm the existence of ejected soil and water on the ground surface, provided there is an appropriate colour contrast between the ground surface and the ejected material. When earthquakes occur in remote regions, satellite imagery therefore has potential use in planning reconnaissance missions. However, highresolution satellite images, like those for Christchurch and the surrounding areas that form the basis of this letter, would be required.

\section{CONCLUSIONS}

The comparison of publicly available GeoEye-1 images with on-ground reconnaissance confirms that, provided there is sufficient colour contrast between the ejecta and the surrounding ground, satellite imagery gives a useful visual indication of where liquefaction has occurred. However, when large volumes of water are ejected along with sand, there may be a false indication of the quantity of ejecta present. Use of satellite imagery has potential use in planning post-earthquake reconnaissance into remote areas.

\section{REFERENCES}

Allen, J., Ashford, S., Bowman, E., et al. (2010). Geotechnical reconnaissance of the 2010 Darfield (Canterbury) earthquake. Bull. New Zealand Soc. Earthquake Engng 43, No. 4, 243-320. Bray, J. \& Frost, D. (2010). Geo-engineering reconnaissance of the 
February 27, 2010 Maule, Chile earthquake. See http://www. geerassociation.org/GEER_Post $\% 20$ EQ\%20Reports/Maule Chile_2010/Ver2_Maule_Chile_2010_index.html. Accessed 25/05/2012.

Cubrinovski, M., Bradley, B., Wotherspoon, L., et al. (2011). Geotechnical aspects of the 22 February 2011 Christchurch Earthquake. Bull. New Zealand Soc. Earthquake Engng 44, No. 4, 205-226.

GeoEye-1 Inc. (2011). GeoEye-1 fact sheet. See http://www.
geoeye.com/CorpSite/assets/docs/brochures/GeoEye-1_Fact_ Sheet.pdf. Accessed 25/05/2012.

Google Earth (2010). http://www.google.com/earth/index.html.

Ishihara, K., Acacio, A. A. \& Towhata, I. (1993). Liquefactioninduced ground damage in Dagupan in the July 16, 1990 Luzon earthquake. Soils and Found 33, No. 1, 133-154.

JGS (Japanese Geotechnical Society) (2004). Photographs and motion picture of the Niigata city immediately after earthquake in 1964. Tokyo: Japanese Geotechnical Society.

\section{WHAT DO YOU THINK?}

To discuss this paper, please email up to 500 words to the editor at journals@ice.org.uk. Your contribution will be forwarded to the author(s) for a reply and, if considered appropriate by the editorial panel, will be published as a discussion. 